\title{
THE GAS-SOLID TRICKLE-FLOW REACTOR FOR THE CATALYTIC OXIDATION OF HYDROGEN SULPHIDE: A TRICKLE-PHASE MODEL
}

\author{
A. B. VERVER ${ }^{\dagger}$ and W. P. M. VAN SWAAIJ \\ Department of Chemical Technology, Twente University of Technology, P.O. Box 217, 7500 AE Enschede, \\ The Netherlands.
}

(Received 25 June 1984)

\begin{abstract}
The oxidation of $\mathrm{H}_{2} \mathrm{~S}$ by $\mathrm{O}_{2}$ producing elemental sulphur has been studied at temperatures of $100-300^{\circ} \mathrm{C}$ and at atmospheric pressure in a laboratory-scalc gas-solid trickle-flow reactor. In this reactor one of the reaction products, i.e. sulphur, is removed continuously by flowing solids. A porous, free-flowing catalyst carrier has been used which contains a NaX zeolite acting as a catalyst as well as a sulphur adsorbent. In order to describe mass transfer in the trickle-flow reactor, a reactor model has been developed in which a particle-free, upflowing gas phase and a dense, downflowing gas-solids suspension, the so-called trickle phase, are distinguished. Within the trick le phase, diffusion of the reactants parallel to reaction in the catalyst particles takes place. The mass transfer rate from the gas phase to the trickle phase has been evaluated by the reaction of $\mathrm{H}_{2} \mathrm{~S}$ with $\mathrm{SO}_{2}$, which is a much faster reaction than the reaction with $\mathrm{O}_{2}$. From the experiments and from the reactor model calculations it appears that for the $\mathrm{H}_{2} \mathrm{~S}-\mathrm{O}_{2}$ reaction no mass transfer limitations occur at temperatures up to about $200^{\circ} \mathrm{C}$, whereas at $300^{\circ} \mathrm{C}$ gas-phase mass transfer and diffusion within the dense solids suspension offer resistance to reaction.
\end{abstract}

\section{INTRODUCTION}

Industrial fuel gases commonly contain sulphur compounds as natural constituents or as unavoidable byproducts of, for example, gasification of solid fuels. Due to corrosion and air pollution problems, desulphurization is usually required. Sulphur contaminants of fuel gases consist mainly of $\mathrm{H}_{2} \mathrm{~S}$, for which many industrial gas-treating systems are known (see, e.g., Kohl and Riesenfeld, 1979). Most of these processes are liquid-absorption processes producing a concentrated $\mathrm{H}_{2} \mathrm{~S}$ gas suitable for a Claus unit (e.g. the alkanolamine processes) or producing elemental sulphur (e.g. the Giammarco-Vetrocoke and the Stretford processes). Besides liquid-absorption processes, dry processes have been developed, such as the Sulfreen process. Dry desulphurization processes producing elemental sulphur are usually based on the reactions of the Claus process. However, because the reactor temperature is between 120 and $150^{\circ} \mathrm{C}$, the sulphur condenses on the porous active carbon or alumina catalyst from which it is periodically removed by heating. These catalytic conversion processes usually require stoichiometric amounts of $\mathrm{SO}_{2}$ to be added to the feed gas.

In our laboratory we are studying a catalytic desulphurization process in which $\mathrm{H}_{2} \mathrm{~S}$ is converted to sulphur by means of $\mathrm{O}_{2}$ or $\mathrm{SO}_{2}$ at temperatures of $150-300^{\circ} \mathrm{C}$ (Verver, 1984). Sulphur is absorbed on the catalyst and continuously removed from the reactor while in a separate stripper section, sulphur is recovered from the catalyst. The reactor/adsorber is a dilute-phase gas-solid contactor, the so-called

${ }^{\dagger}$ Present address: Akzo Engineering B.V., P.O. Box 209, $6800 \mathrm{LV}$ Arnhem, The Netherlands. gas-solid trickle-flow contactor, which combines a continuous, counter-current operation with high mass transfer rates and a low pressure drop. Besides this, high $\mathrm{H}_{2} \mathrm{~S}$-removal efficiencies can be expected due to the counter-current adsorption of sulphur vapour, as the $\mathrm{H}_{2} \mathrm{~S}$ conversion is restricted by the thermodynamic equilibrium in the gas phase between $\mathrm{H}_{2} \mathrm{~S}, \mathrm{SO}_{2}, \mathrm{~S}$ and $\mathrm{H}_{2} \mathrm{O}$. At high temperatures $\left(>250^{\circ} \mathrm{C}\right)$ and high $\mathrm{H}_{2} \mathrm{O}$ contents this could become an important factor (Verver, 1984).

The catalyst for this process is preferably a synthetic zeolite, $\mathrm{NaX}$, because of its high selectivity to elemental sulphur and its high reactivity (Johnson and Kerr, 1961). Because of the remarkable sulphur adsorption properties (Barrer and Whiteman, 1967) sulphur adsorption proceeds up to temperatures of about $250^{\circ} \mathrm{C}$. In a previous investigation the reaction rate of the $\mathrm{H}_{2} \mathrm{~S}-\mathrm{O}_{2}$ reaction over several $\mathrm{X}$ and $\mathrm{Y}$ type zeolites and sulphur adsorption properties have been determined (Verver and Van Swaaij, 1985). Amongst these catalysts the $\mathrm{NaX}$ type is the most reactive catalyst and adsorbs sulphur from the $\mathrm{H}_{2} \mathrm{~S}$ oxidation most strongly. In the present study we used $\mathrm{NaX}$ zeolite embedded in silica-alumina particles which are in many respects similar to the highly porous zeolitic fluid cracking catalysts widely applied in the petrochemical industry. These particles are known to exhibit an excellent mechanical behaviour in fluid bed and gas-solid trickle flow systems.

Our laboratory-scale apparatus is largely based on previous work of Roes and Van Swaaij (1979a-c) on gas-solid trickle flow over packed columns. In this contactor, solid particles are flowing as a finely dispersed phase over a packing, counter-currently to an upward gas flow. To avoid stagnant solids hold-up we developed regularly stacked packings adapted particu- 
larly to gas-solid contacting (Verver and Van Swaaij, $1986 \mathrm{a}, \mathrm{b}$ ). The present laboratory-scale $\mathrm{H}_{2} \mathrm{~S}$-oxidation reactor was designed as a simulation of two parallel channels of such a regularly stacked packing. Basic data on the kinetics of the $\mathrm{H}_{2} \mathrm{~S}-\mathrm{O}_{2}$ reaction over the zeolitic catalyst used in the reactor were obtained from separate measurements in a thermobalance apparatus (Verver, 1984). At the present reactor conditions an overall first-order kinetics appeared to be applicable. Data on the catalyst hold-up in the reactor can be obtained by tracer experiments in the solids phase. Results obtained at the low solids mass fluxes typically used in the $\mathrm{H}_{2}$ S-oxidation reactor will be presented here.

Apart from chemical reaction rate and catalyst holdup, the performance of the reactor depends on mass transfer rates between gas and catalyst. In a dilute gas-solid system such as the gas-solid trickle-flow reactor, high mass transfer rates from gas to suspended solids can be expected because of the high interfacial surface areas exposed, particularly in the case of small particles. However, formation of less dilute suspensions (e.g. clouds or trick les) might affect mass transfer rates strongly, similar to mass transfer in fluid bed reactors. Formation of trickles, as we will call this phenomenon from its appearance in the packed column of Roes and Van Swaaij, is likely to occur due to the favourable reduction of friction forces experienced by particles moving in a more or less agglomerated state. Recently, we reported for several types of particles a decreasing pressure drop per volume of solids at increasing solids concentration (Verver and Van Swaaij, 1986a), particularly in the case of small particles. Therefore, in modelling the gas-solid trickleflow reactor these phenomena have to be taken into account. This paper describes a first attempt at such a model.

\section{THEORETICAL}

\section{Gas-phase mass transfer}

The flow phenomena of gas and solid particles in a gas-solid trickle-flow contactor are extremely complex. Therefore, in modelling the reactor many unknown parameters exist. As a first attempt to correlate experimental data we developed a model based on the general concept of a two-phase counter-current flow system with mass transfer to the solids phase and reaction in the solids phase (see, e.g., Westerterp et al., 1984). The gas phase is flowing on avcragc in an upward direction (Fig. 1), more or less in plug flow. Deviations from plug flow can be described by the axially dispersed plug flow model. The solids phase is flowing downward, also in plug flow with axial dispersion. Axial mixing in the solids phase has only a small effect on reactor performance and, therefore, it will not be taken into consideration. Axial mixing in the gas phase has been studied by Roes and Van Swaaij (1979b) using a packed column of Pall rings and by Noordergraaf et al. (1980) using a baffle column. It was found that the gas-phase Péclet number depends on

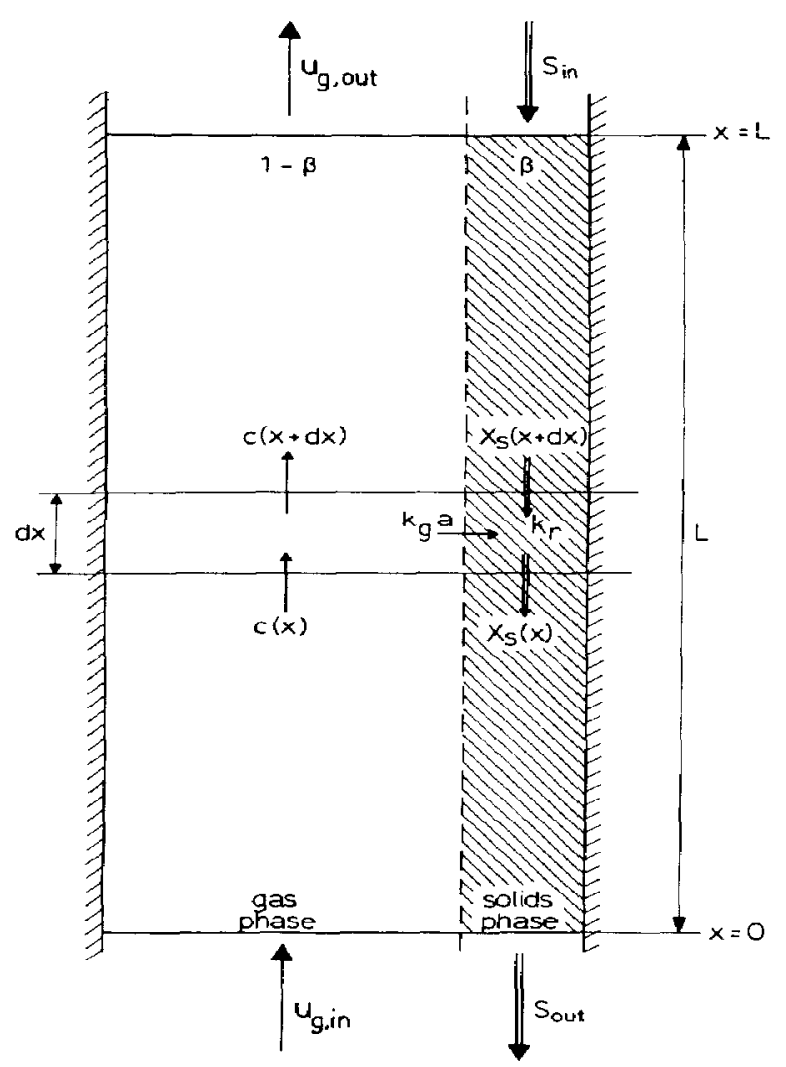

Fig. 1. Two-phase counter-current flow model.

the gas and solids mass fluxes. At relatively high superficial gas velocities of $0.10-0.20 \mathrm{~m} \mathrm{~s}^{-1}$, axial mixing in the gas phase is low. For $P e / L$, values between 20 and $80 \mathrm{~m}^{-1}$ were found. In our work, very low solids mass fluxes $\left(0.01-0.05 \mathrm{~kg} \mathrm{~m}^{-2} \mathrm{~s}^{-1}\right)$ and relatively high superficial gas velocities $\left(0.10-0.20 \mathrm{~m} \mathrm{~s}^{-1}\right)$ are used. At these conditions a Péclet number of about 20 can be expected, which corresponds to a number of mixing units sufficiently high to neglect the effect of axial mixing and assume plug flow behaviour (Westerterp et al., 1984). In this case, the differential equation for the reactant concentration in the gas phase is given as:

$$
\frac{\mathrm{d} c}{\mathrm{~d} x}=-\frac{k_{\mathrm{g}} a}{\omega_{\mathrm{g}}}\left(c-c_{\mathrm{i}}\right)
$$

with the boundary condition at the inlet: $c(x=0)=c_{\text {in }}$.

In general, the interfacial concentration $c_{\mathrm{i}}$ depends on gas-phase and solids-phase mass transfer coefficients. For an instantaneous reaction, $c_{\mathrm{i}}$ approaches zero in which case eq. (1) can be simplified. Integration results in:

$$
k_{\mathrm{g}} a=-u_{\mathrm{g}} / L \cdot \ln \left(c_{\mathrm{out}} / c_{\mathrm{in}}\right) .
$$

\section{Mass transfer in the trickle phase}

In eq. (1), $k_{\mathrm{g}} a$ is the mass transfer constant in the gas phase, in which $a$ is the interfacial surface area for mass transfer. As we discussed before (Verver and Van 
Swaaij, 1984), the interfacial surface area might be much smaller than the external surface area of the particles, owing to the formation of solid particle agglomerates. For a fast reaction, concentration gradients might arise within such agglomerates, and mass transfer and reaction would proceed partially in parallel. In order to take account of such effects we developed the trickle model, in which the solids are supposed to flow in a dense gas-solids suspension phase, see Fig. 2. This is an extreme case of solids agglomeration and so we neglected the effect of gas flow in the solids suspension phase. For a first-order reaction, the mass transfer rate of the reactant to the trickle phase can be written as:

$$
k_{\mathrm{g}} a\left(c-c_{\mathrm{i}}\right)=\beta k_{\mathrm{r}} c_{\mathrm{i}} \eta_{\mathrm{tr}}
$$

where $k_{\mathrm{r}}$ is the first-order rate constant (per unit volume of catalyst) and $\beta$ is the catalyst hold-up in the reactor. These parameters can be determined separately by kinetic and hydrodynamic measurements. The interfacial concentration $c_{\mathrm{i}}$ is eliminated by defining an overall rate constant:

$$
k_{\mathrm{ov}}=1 /\left(\frac{1}{k_{\mathrm{g}} a}+\frac{1}{k_{\mathrm{r}} \beta \eta_{\mathrm{tr}}}\right)
$$

Substitution of the equations above in eq. (1) gives the differential equation:

$$
\frac{\mathrm{d} c}{\mathrm{~d} x}=-k_{\mathrm{ov}} c / u_{\mathrm{g}}
$$

with boundary condition: $c(x=0)=c_{\text {in }}$.

If $k_{\mathrm{g}} a$ and $k_{\mathrm{r}} \beta \eta_{\mathrm{tr}}$ are constant throughout the reactor, eq. (5) can be integrated, giving:

$$
k_{\text {ov }}=u_{\mathrm{g}} / L \cdot \ln \left(c_{\text {out }} / c_{\text {in }}\right) .
$$

The trickle phase is assumed to be a homogeneous, stagnant medium, in which reaction takes place parallel to reactant diffusion. The effectiveness factor of the

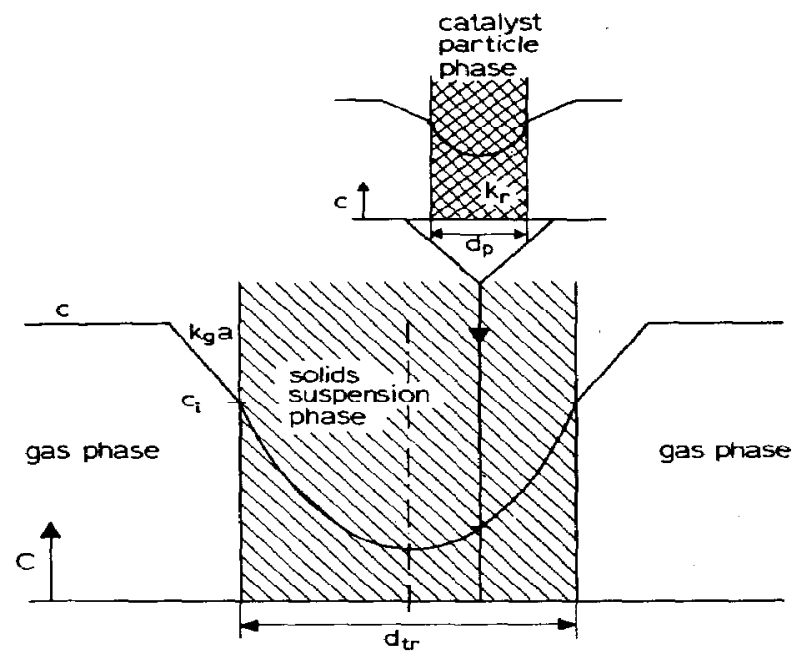

Fig. 2. Trickle-phase model (with concentration profiles for substantial mass transfer limitations in trickle phase and catalyst particle phase). trickle phase, $\eta_{\mathrm{tr}}$, can be calculated from the Thiele modulus, which is given for a first-order reaction as:

$$
\begin{gathered}
\eta_{\mathrm{tr}}=\frac{\tanh \phi_{\mathrm{tr}}}{\phi_{\mathrm{tr}}} \\
\phi_{\mathrm{tr}}=\frac{V_{\mathrm{tr}}}{A_{\mathrm{tr}}}\left(\frac{\left(1-\varepsilon_{\mathrm{tr}}\right) k_{\mathrm{r}}}{D_{\mathrm{tr}, \mathrm{efr}}}\right)^{1 / 2}
\end{gathered}
$$

where $\varepsilon_{\mathrm{tr}}$ is the porosity of the gas-solids suspension phase. The Thiele modulus, $\phi_{\mathrm{tr}}$, clearly depends on the diameter and shape of the trickles. As a first approximation, we assumed a cylindrical geometry of the trickles. The minimum number of trickles was supposed to be equal to 2 as the reactor exhibits two channels for solids flow. The average diameter of a trickle is then given by:

$$
d_{\mathrm{tr}}=\left(\frac{1}{l-\varepsilon_{\mathrm{tr}}} \frac{4}{\pi I / A} \frac{\beta V_{\mathrm{r}}}{2}\right)^{1 / 2}
$$

and the Thiele modulus is estimated as:

$$
\phi_{\mathrm{tr}}=\frac{d_{\mathrm{tr}}}{4}\left(\frac{\left(1-\varepsilon_{\mathrm{tr}}\right) k_{\mathrm{r}}}{D_{\mathrm{tr}, \mathrm{eff}}}\right)^{1 / 2}=\left(\frac{V_{\mathrm{r}}}{8 \pi L \theta} \frac{k_{\mathrm{r}}}{D_{\mathrm{tr}, \mathrm{efr}}} \beta\right)^{1 / 2}
$$

The tortuosity factor of the trickle phase, $\theta$, corrects for the increased length of a trickle due to the zig-zag shape of trickles of solid particles, as they are formed at trickle flow over the column internals. The value of $\theta$ is probably between 1 and $\sqrt{2}$, but for the present approximation, a value of 1 will be used.

For the diffusion coefficient in the trickle phase, $D_{\text {tr. eff }}$, the equation for bulk diffusion in a macroporous medium will be used (Satterfield, 1970):

$$
D_{\mathrm{tr}, \mathrm{eff}}=\varepsilon_{\mathrm{tr}}^{2} D \text {. }
$$

However, the porosity of the trickle phase, $f_{\mathrm{tr}}$, is not easily measured and an assumption has to be made. The most significant effect of $D_{t r, \text { eff }}$ on $\phi_{t r}$ is encountered in the case of strong diffusional limitations, i.e. $\phi_{\mathrm{tr}}>1$. Then, $\eta_{\mathrm{tr}}$ approaches $1 / \phi_{\mathrm{tr}}[$ eq. (7)] and becomes proportional to $D_{t r, e f f}^{0.5}$. From eq. (11), this would result in a decrease of $\eta_{\mathrm{tr}}$ of, for example, $20 \%$ in case of $\varepsilon_{\mathrm{tr}}$ decreasing to $80 \%$. A porosity as low as $80 \%$ is not that likely to occur in our experiments because of the low (average) solids concentrations encountered, always less than $1 \%$. Apparently, although $\eta_{t r}$ can be affected by the porosity of the trickle, the effect is not likely to be of great importance.

\section{CATALYST PROPERTIES}

A porous, microspherical silica-alumina catalyst was used in which $18.5 \mathrm{wt} \% \mathrm{NaX}$ (Linde SK20 sieve) was embedded. This catalyst was prepared and provided by Akzo Chemie B.V., Research Centre Amsterdam. Physical properties of the catalyst are summarized in Table 1. By X-ray powder diffraction, the presence of $\mathrm{NaX}$-type zeolite crystals in the catalyst could be observed clearly. Gravimetric measurements in a thermobalance apparatus have shown a maximum sulphur uptake of about $6.0-6.5 \mathrm{wt} \%$ at low relative 
Table 1. Catalyst properties

Zeolite content

Sodium content

Average bulk density

Particle density

Particle void fraction

Weight loss at $1000^{\circ} \mathrm{C}$

Particle size cistribution:

diameter $(\mu \mathrm{m})$

$<149$

$<105$

$<80$

$<40$

$<20$

Mean particle diameter

Sulphur adsorption capacity ${ }^{\dagger}$

${ }^{\dagger}$ As given by Verver (1984).

sulphur vapour pressures (Verver, 1984). This figurc corresponds quantitatively to the sulphur adsorption capacity of the zeolite, which indicates that sulphur is adsorbed mainly by the zeolite embedded.

In the thermobalance set-up, reaction rate measurements for the $\mathrm{H}_{2} \mathrm{~S}-\mathrm{O}_{2}$ reaction have been carried out as well, at temperatures up to $200^{\circ} \mathrm{C}$. The reaction rate is determined primarily by the zeolite embedded in the catalyst (Verver, 1984). At increasing sulphur load, the reaction rate slowly decreases. For example, at $X_{\mathrm{S}}$ $=0.04 \mathrm{~kg} \mathrm{~S} \mathrm{~kg}^{-1}$ the reaction rate dropped to $50 \%$ of its maximum value, which was observed at a sulphur load of about $0.01 \mathrm{~kg} \mathrm{~S} \mathrm{~kg}^{-1}$.

Kinetics of the $\mathrm{H}_{2} \mathrm{~S}-\mathrm{O}_{2}$ reaction over the zeolitic catalyst are rather complicated, but at the present reactor conditions, i.e. low $\mathrm{H}_{2} \mathrm{~S}$ and $\mathrm{O}_{2}$ partial pressures and a $\mathrm{H}_{2} \mathrm{~S} / \mathrm{O}_{2}$ molar ratio of 2.0 , first-order kinetics appears to be adequate. For the chemical reaction rate a first-order rate constant has been given (Verver, 1984):

$$
\begin{aligned}
k_{\text {chem }} & =\left\{66.0 \times 10^{\circ} \exp (-E / R T)\right\} \mathrm{s}^{-1} \\
\left(\text { at } X_{\mathrm{S}}\right. & \left.=0.01 \mathrm{~kg} \mathrm{~S} \mathrm{~kg}^{-1}\right) \\
\text { with } E & =52 \times 10^{3} \mathrm{~J} \mathrm{~mol}^{-1} .
\end{aligned}
$$

At elevated temperatures the reaction rate might become affected by intraparticle mass transfer (pore diffusion) resistance. For the catalyst used, being a FCC-like material, pore dimensions are small and internal diffusion is dominated by Knudsen diffusion. The effective, intraparticle diffusion coefficient then becomes (Satterfield, 1970):

$$
D_{\mathrm{p}, \mathrm{eff}}=\frac{\xi_{\mathrm{p}}}{\tau_{\mathrm{p}}} D_{\mathrm{kn}}=\underset{\tau_{\mathrm{p}}}{\varepsilon_{\mathrm{p}}} \frac{d_{\mathrm{pore}}}{3}(8 R T / \pi M)^{0.5}
$$

From particle data we estimated the average pore diameter $d_{\text {pore }}$ to be about $4.5 \times 10^{-9} \mathrm{~m}$, and for the tortuosity factor $\tau_{p}$ a value of 2.0 was assumed. The effective, intraparticle diffusion coefficient for $\mathrm{O}_{2}$ at $200^{\circ} \mathrm{C}$ then amounts to about $0.2 \times 10^{-6} \mathrm{~m}^{2} \mathrm{~s}^{-1}$. The Thiele modulus for the catalyst particle, $\phi_{\mathbf{p}}$, which is given as

$$
\phi_{\mathrm{p}}=\frac{V_{\mathrm{p}}}{A_{\mathrm{p}}}\left(k_{\mathrm{chern}} / D_{\mathrm{p}, \mathrm{eff}}\right)^{0.5}
$$

then amounts to 0.28 for the $\mathrm{H}_{2} \mathrm{~S}-\mathrm{O}_{2}$ reaction at $200^{\circ} \mathrm{C}$. The effectiveness factor $\eta_{\mathrm{p}}$ is calculated from the equation given by Satterfield (1970) for a spherical particle:

$$
\eta_{\mathrm{p}}=\frac{1}{\phi_{\mathrm{p}}}\left[1 / \tanh \left(3 \phi_{\mathrm{p}}\right)-1 /\left(3 \phi_{\mathrm{p}}\right)\right]
$$

resulting in a value of 0.96 . At $200^{\circ} \mathrm{C}$, the reaction appears to proceed almost homogeneously throughout the catalyst. At higher temperatures, $\eta_{\mathrm{p}}$ will decrease; e.g. at $300^{\circ} \mathrm{C}, \eta_{\mathrm{p}}$ has dropped to about 0.75 . The effect of pore diffusion is taken into account by using the apparent reaction rate constant $k_{r}$, defined as $k_{\text {chem }} \eta_{p}$. Table 2 shows the resulting data.

The oxidation of $\mathrm{H}_{2} \mathrm{~S}$ to sulphur is an exothermic reaction with a heat effect of about $200 \mathrm{~kJ}$ per mole $\mathrm{H}_{2} \mathrm{~S}$ (Gamson and Elkins, 1953). This causes temperature gradients in the solid particles and it might affect the effectiveness factor. However, according to the theory of Weis $z$ and Hicks (1962), thermal effects can be neglected in our case, because of the low reactant concentrations.

\section{THE GAS-SOLID TRICKLE-FLOW REACTOR}

The gas-solid reactor was a double-channel baffle column with a cross-sectional area of $0.06 \times 0.06 \mathrm{~m}$ and an effective length of $0.6 \mathrm{~m}$ (see Fig. 3). The arrangement of the baffles was geometrically similar to those of the single-channel zig-zag column studied by Noordergraaf et $a l$. (1980). The angle of declination of the baffles was set to $45^{\circ}$ in order to avoid any accumulation of solids. This baffle column was considered a two-channel model of the regularly stacked column packing developed for gas-solid trickle flow with a low pressure drop at high gas velocities (Verver and Van Swaaij, 1986a).

The reactor was submerged in a fluid bed furnace (diameter $0.19 \mathrm{~m}$, total length about $1.6 \mathrm{~m}$ ) of FCC particles, which was heated by an electric heating clement (Fig. 4). The temperature gradient along the reactor was found to be negligible, i.e. less than $3^{\circ} \mathrm{C}$ at a temperature level of about $300^{\circ} \mathrm{C}$. The reactor feed gas contained about 1.0 vol $\% \mathrm{H}_{2} \mathrm{~S}$ and a stoichiometric amount of $\mathrm{O}_{2}$, or occasionally an excess of $\mathrm{SO}_{2}$. The flow rate was adjusted and measured by calibrated

Table 2. Calculated data for the apparent reaction rate of the $\mathrm{H}_{2}$ S-oxidation reaction

\begin{tabular}{cccccr}
$T$ & $\begin{array}{c}10^{6} \times \mathrm{D}_{\mathrm{p}, \text { cff }} \\
\left(\mathrm{m}^{2} \mathrm{~s}^{-1}\right)\end{array}$ & $\begin{array}{c}k_{\mathrm{chem}} \\
\left(\mathrm{s}^{-1}\right)\end{array}$ & $\phi_{\mathrm{p}}$ & \multicolumn{1}{c}{$\eta_{\mathrm{p}}$} & \multicolumn{1}{c}{$\begin{array}{c}\boldsymbol{k}_{\mathrm{T}} \\
\left(\mathrm{s}^{-1}\right)\end{array}$} \\
\hline 150 & 0.20 & 25 & 0.13 & 0.98 & 24 \\
200 & 0.21 & 120 & 0.28 & 0.96 & 114 \\
250 & 0.22 & 410 & 0.51 & 0.87 & 365 \\
300 & 0.23 & 1200 & 0.79 & 0.75 & 900 \\
350 & 0.24 & 2900 & 1.4 & 0.56 & 1600 \\
\hline
\end{tabular}


The gas-solid trickle-flow reactor

(a)

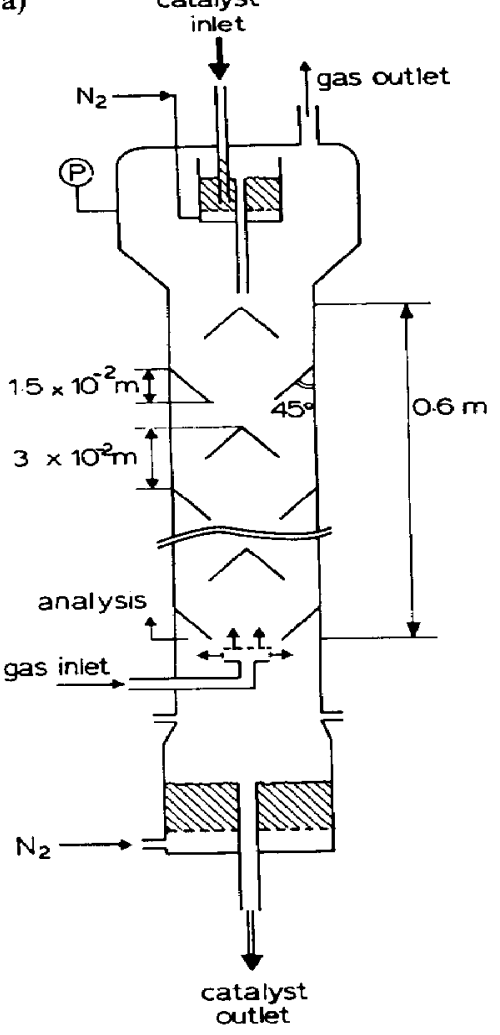

(b)

trickle flow section;

$\varnothing 0.06 \mathrm{~m}$

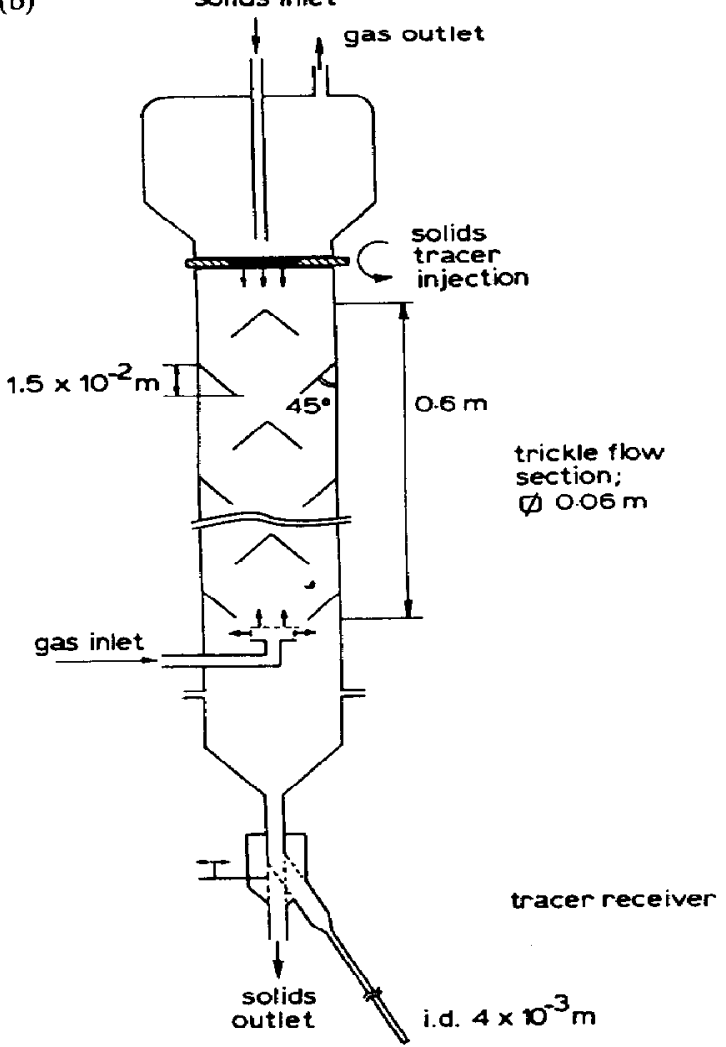

Fig. 3. The gas-solid trickle-flow reactor (a) for $\mathrm{H}_{2} \mathrm{~S}$-oxidation (b) for solids hold-up measurements.

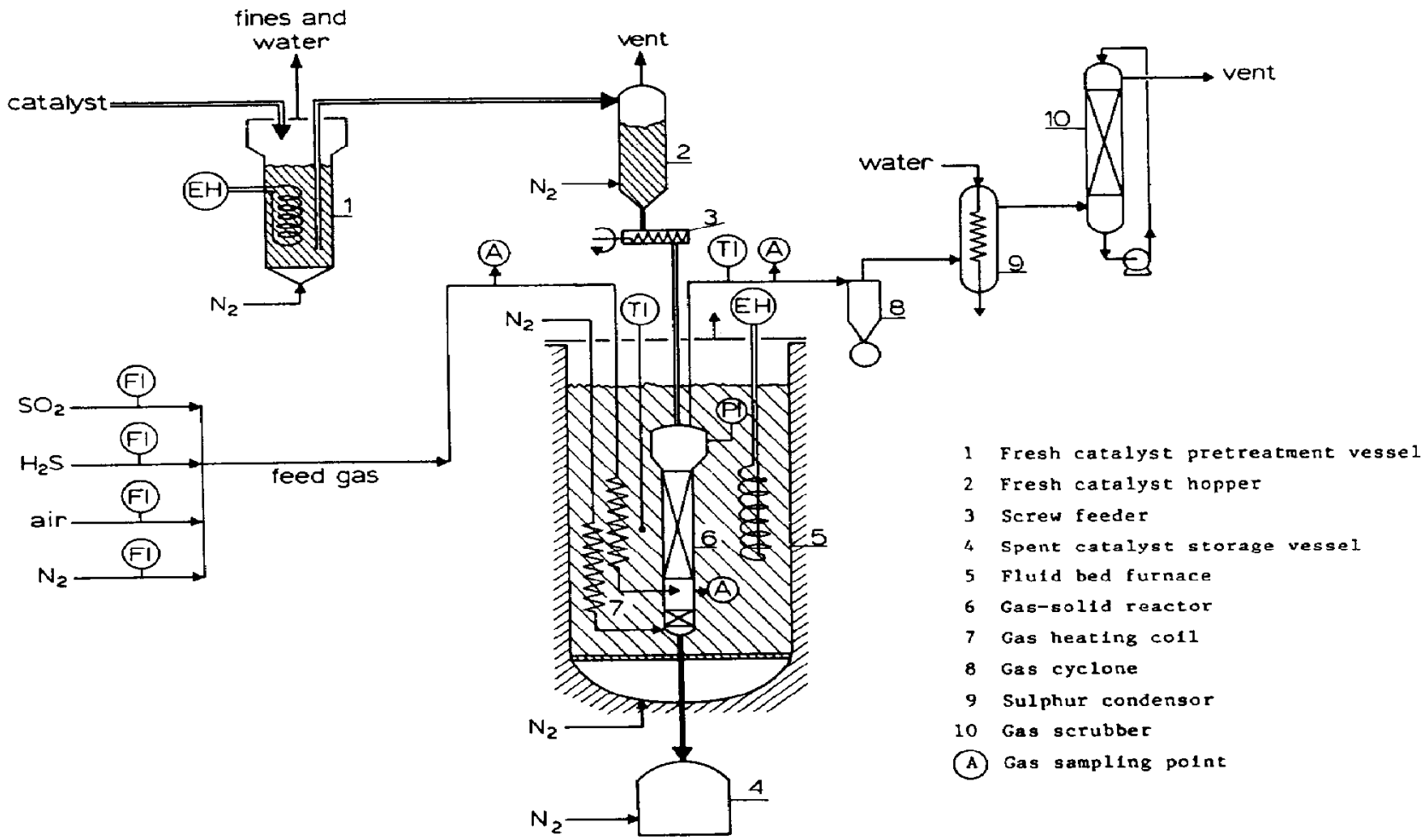

Fig. 4. Experimental set-up of the $\mathrm{H}_{2} \mathrm{~S}$-oxidation reactor. 
flowmeters. The gas flow was preheated in a glass coil submerged in the fluid bed furnace. Temperatures inside the reactor were measured occasionally by inserting thermocouples. The temperature in the reactor was equal to the temperature of the surrounding fluid bed to within about $4^{\circ} \mathrm{C}$.

Before the catalyst particles were fed to the reactor, they were dried at a temperature of about $150-200^{\circ} \mathrm{C}$ in a nitrogen-fluidized bed (1) for a couple of hours. Simultaneously, fines were removed. The catalyst flow rate through the reactor was controlled by a calibrated screw-feeder (3). The solids flow rate could be varied from about $0.02 \times 10^{-3}$ to $0.2 \times 10^{-3} \mathrm{~kg} \mathrm{~s}^{-1}$. The catalyst was fed to the reactor via a small fluid bed seal in the top of the reactor (see Fig. 3a) to prevent early contact with reactor gas. In this device, the catalyst flow was heated as well. A few additional experiments in which the catalyst flow to the reactor was preheated separately by means of a small, electrically heated fluid bed resulted in the same performance of the reactor. Particles leaving the reactor were collected in a storage vessel (4). Gas leaving the reactor passed through a cyclone to separate any entrained particles. Reactor gas composition was analysed by taking small sample flows to a gas chromatograph. The $\mathrm{H}_{2} \mathrm{~S}, \mathrm{SO}_{2}$ and $\mathrm{O}_{2}$ content could be determined (details are given by Verver, 1984). In order to obtain data at steady-state conditions, the reactor was left running at each gas and solids mass flow rate for about $15 \mathrm{~min}$, after which the conversion had become constant.

In the gas-phase mass transfer measurements, $\mathrm{O}_{2}$ was rcplaced by $\mathrm{SO}_{2}$ to obtain a much faster reaction. The $\mathrm{H}_{2} \mathrm{~S}$ content of the feed gas was lowered to $0.5 \mathrm{vol} \%$, to avoid too high sulphur loads of the catalyst. Using a reaction gas with $0.6 \mathrm{vol} \%$ of $\mathrm{SO}_{2}$, a $\sim 2.4$-fold excess of $\mathrm{SO}_{2}$ was obtained.

\section{SOLIDS HOLD-UP MEASUREMENTS}

For solids hold-up measurements at ambient conditions a full-scale perspex copy of the $\mathrm{H}_{2}$ S-oxidation reactor was used (Fig. 3b). Solids hold-up can be evaluated from residence time distribution (RTD) experiments in the solids phase (Roes and Van Swaaij, 1979b). The experimental technique comprises the injection of a small amount of black particles into the solids feed and measuring the response curve at the outlet by a reflectometcr. Bccausc of the low solids fluxes, we collected the solids from the column in a narrow glass tube. The RTD experiments were carried out with silica-alumina particles (FCC) such as were used previously by Roes and Van Swaaij (1979a) and by Noordergraaf et al. (1980). Although the chemical composition is different because of the absence of zeolite, physical properties are nearly identical to the NaX catalyst particles, and therefore, the hydrodynamic behaviour will be similar.

Tracer pulse experiments were carried out at zero gas velocity and at a superficial gas velocity of $0.15 \mathrm{~m} \mathrm{~s}^{-1}$. From the response to an ideal delta function of tracer particles, the mean residence time of the particles in the column can be calculated:

$$
\bar{\tau}=\frac{\sum t_{\mathrm{i}} C_{\mathrm{i}} \Delta t}{\sum C_{\mathrm{i}} \Delta t} .
$$

From this, the average solids hold-up in the column is derived:

$$
\beta=\frac{S}{\rho_{\mathrm{p}} u_{\mathrm{p}}}=\frac{S}{\rho_{\mathrm{p}} L} \bar{\tau}
$$

In Table 3 the data on the mean residence time calculated from the response curves are summarized. Each value is the average value from three pulse experiments. For both gas velocities, $\bar{\tau}$ is decreasing at increasing $S$. This means that the solids velocity, calculated as $L / \bar{\tau}$, is increasing with $S$. Operating at higher $S\left(1-6 \mathrm{~kg} \mathrm{~m}^{-2} \mathrm{~s}^{-1}\right)$ and at low $u_{\mathrm{g}}$, Roes and Van Swaaij (1979a) have observed in a packed column of Pall rings a constant particle velocity of about $0.17 \mathrm{~m} \mathrm{~s}^{-1}$. In our experiments, at $S$ $=0.01-0.05 \mathrm{~kg} \mathrm{~m}^{-2} \mathrm{~s}^{-1}$, we observed particle velocities only up to about $0.10 \mathrm{~m} \mathrm{~s}^{-1}$. Obviously, at low solids mass fluxes, the solid particles are slowed down strongly.

At a superficial gas velocity of $0.15 \mathrm{~m} \mathrm{~s}^{-1}, u_{\mathrm{p}}$ is even less than $0.05 \mathrm{~m} \mathrm{~s}^{-1}$. An increase of $u_{\mathrm{p}}$ with $S$ is clearly observable. On the other hand, the mean slip velocity

\begin{tabular}{|c|c|c|c|c|}
\hline$\underset{\left(\mathrm{ms}^{-1}\right)}{u_{\mathrm{g}}}$ & $\begin{array}{c}S \\
\left(\mathrm{~kg} \mathrm{~m}^{-2} \mathrm{~s}^{-1}\right)\end{array}$ & $\begin{array}{c}\bar{\tau} \\
(\mathrm{s})\end{array}$ & $\begin{array}{c}u_{p} \\
\left(m s^{-1}\right)\end{array}$ & $\begin{array}{c}10^{3} \times \beta \\
\left(\mathrm{m}^{3} \text { solids } \mathrm{m}^{-3}\right)\end{array}$ \\
\hline 0.0 & 0.006 & $9.3 \pm 0.6$ & 0.065 & 0.11 \\
\hline 0.0 & 0.010 & $5.9 \pm 0.6$ & 0.102 & 0.12 \\
\hline 0.0 & 0.015 & $7.4 \pm 0.7$ & 0.081 & 0.22 \\
\hline 0.0 & 0.020 & $6.8 \pm 0.8$ & 0.088 & 0.28 \\
\hline 0.0 & 0.032 & $7.2 \pm 1.2$ & 0.083 & 0.47 \\
\hline 0.0 & 0.043 & $6.4 \pm 0.6$ & 0.094 & 0.56 \\
\hline 0.0 & 0.055 & $5.6 \pm 0.9$ & 0.107 & 0.63 \\
\hline 0.15 & 0.009 & $16.6 \pm 1.3$ & 0.036 & 0.31 \\
\hline 0.15 & 0.019 & $15.4 \pm 0.4$ & 0.039 & 0.60 \\
\hline 0.15 & 0.030 & $15.1 \pm 0.2$ & 0.040 & 0.93 \\
\hline 0.15 & 0.041 & $13.1 \pm 0.3$ & 0.046 & 1.10 \\
\hline 0.15 & 0.050 & $12.8 \pm 0.5$ & 0.047 & 1.31 \\
\hline
\end{tabular}

Table 3. Experimental results of the solids hold-up measurements 
between the gas phase and solids phase still exceeds the terminal velocity of the particles (about $0.13 \mathrm{~m} \mathrm{~s}^{-1}$ ). In order to maintain a net downflow of solid particles, the mean drag force exerting on the particles must have been reduced, due to, for example, solids agglomeration or trickle formation. These phenomena were studied separately (Verver and Van Swaaij, 1986a). The solids hold-up $\beta$, as determined from the mean residence time of the solids, is plotted vs the solids mass flux in Fig. 5. Related to the lower solids velocity, the solids hold-up is considerably higher, a factor two at least, than the value according to the data extrapolated from the packed column experiments of Roes and Van Swaaij (1979a). From the above, it should be concluded that at increasing solids mass fiuxes, agglomeration of solids or trickle formation becomes increasingly important, which might affect mass transfer properties in particular.

\section{$H_{2}$ S-OXIDATION EXPERIMENTS}

In the $\mathrm{H}_{2} \mathrm{~S}$-oxidation reactor the conversion of $\mathrm{H}_{2} \mathrm{~S}$ and $\mathrm{O}_{2}$ was measured at steady-state conditions for feed gases containing $\mathrm{H}_{2} \mathrm{~S}$ and stoichiometric amounts of $\mathrm{O}_{2}$. Adsorption of $\mathrm{H}_{2} \mathrm{~S}$ on the catalyst flow was found to be negligible compared with the consumption of $\mathrm{H}_{2} \mathrm{~S}$ by the reaction. At all reaction conditions the molar conversion of $\mathrm{H}_{2} \mathrm{~S}$ and $\mathrm{O}_{2}$ was in agreement with the stoichiometry of the oxidation of $\mathrm{H}_{2} \mathrm{~S}$ to sulphur (i.e. 2 moles $\mathrm{H}_{2} \mathrm{~S}$ per mole $\mathrm{O}_{2}$ ) to within $10 \%$. Only at a reaction temperature of $300^{\circ} \mathrm{C}$, could traces of $\mathrm{SO}_{2}$ be observed in the reactor off-gases. Thermogravimetric analysis of samples collected at the solids outlet of the reactor showed that the sulphur load of the spent catalyst was in fair agreement with the sulphur load calculated from the sulphur mass balance over the reactor. For superficial gas velocities up to $0.19 \mathrm{~m} \mathrm{~s}^{-1}$, the entrainment of catalyst particles from the reactor was less than $10 \%$. At a gas velocity of $0.26 \mathrm{~m} \mathrm{~s}^{-1}$, however, about $40 \%$ of the catalyst par-

$$
\begin{aligned}
& -0 \text { - this work; } u_{g}=0.0 \mathrm{~ms}^{-1} \\
& -O \text { - this work; } u_{g}=0.15 \mathrm{~ms}^{-1} \\
& -- \text { extrapolated from } \mathrm{s}<1 \mathrm{~kg} \mathrm{~m}^{-2} \mathrm{~s}^{-1}, \\
& 0<u_{g}<0.10 \mathrm{~m} \mathrm{~s}^{-1} \text { (Roes \& Van Swaili, } \\
& 1979 \mathrm{a})
\end{aligned}
$$

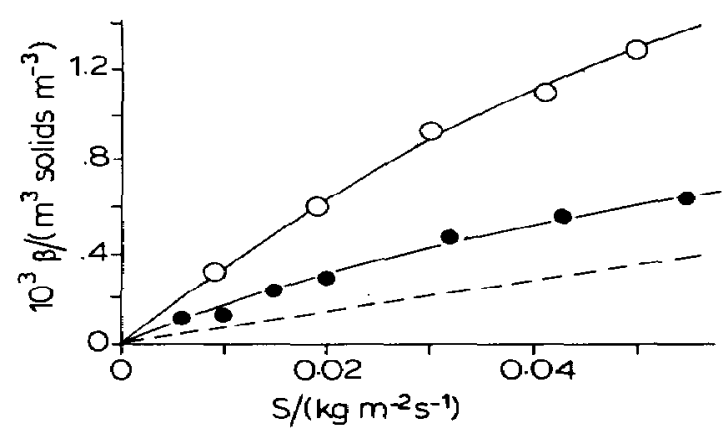

Fig. 5. The solids hold-up from the RTD experiments vs solids mass flux. ticles were carried over to the cyclone, which makes such a high gas velocity unsuitable for experiments with small catalyst particles.

The overall rate constant $k_{\text {ov }}$ was determined from the $\mathrm{O}_{2}$ conversion over the reactor according to eq. (6). Resulting data are presented in Figs 6 and 7. At a gas velocity of $0.15 \mathrm{~m} \mathrm{~s}^{1}$, the value of $k_{\mathrm{ov}}$ increases at increasing catalyst mass flux and at increasing temperature (Fig. 6). Calculations have shown that for $S>0.01 \mathrm{~kg} \mathrm{~m}^{-2} \mathrm{~s}^{-1}$, the catalyst had been loaded only partially with sulphur. At zero catalyst flux, some conversion was still observed. Because the reactant concentration in the gas just below the trickle flow section was close to the off-gas concentration, this could have been caused by backmixing to the lower part of the reactor and reaction over the catalyst holdup present there. Similarly, with catalyst flowing through the reactor, the concentration drop of the gas just below the trickle-flow section was found to be about $10 \%$ at low catalyst fluxes, and about $20 \%$ at higher solids mass fluxes and high reaction temperatures. The data on the overall rate constant $k_{\mathrm{ov}}$ obtained at different superficial gas velocities are plotted in Fig. 7. The $k_{o v}$ value is only slightly affected

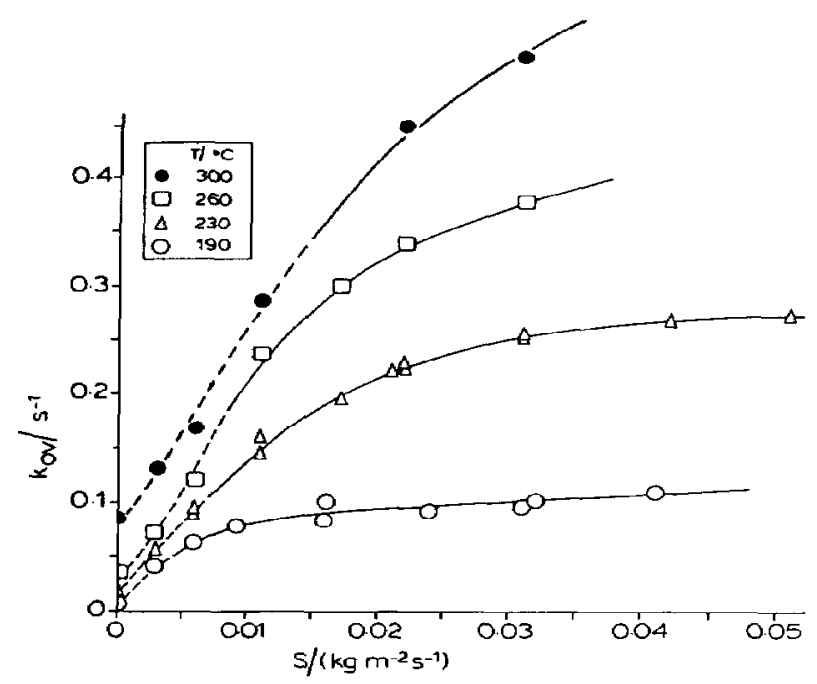

Fig. 6. The experimental overall rate constant vs solids mass flux $\left(u_{\mathrm{g}}=0.15 \mathrm{~m} \mathrm{~s}^{-1}\right)$.

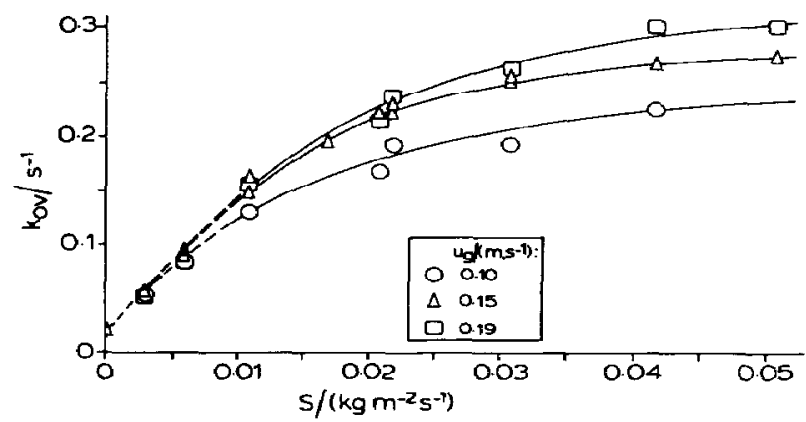

Fig. 7. The experimental overall rate constant vs solids mass flux $\left(T=230^{\circ} \mathrm{C}\right)$. 
by the gas velocity, although an increase of $k_{\mathrm{ov}}$ with $\boldsymbol{u}_{\mathrm{g}}$ can be recognized.

\section{MASS TRANSFER EXPERIMENTS}

Adding $\mathrm{SO}_{2}$ instead of $\mathrm{O}_{2}$ results in an increased $\mathrm{H}_{2} \mathrm{~S}$ conversion over the reactor. Experiments with $\mathrm{SO}_{2}$ have been carried out at temperatures up to $190^{\circ} \mathrm{C}$. Contrary to $\mathrm{H}_{2} \mathrm{~S}, \mathrm{SO}_{2}$ is adsorbed on the flowing catalyst in substantial amounts, i.e. up to about $2 \mathrm{wt} \% \mathrm{SO}_{2}$ at 150 and $190^{\circ} \mathrm{C}$. As the feed gas contains an excess of $\mathrm{SO}_{2}$, the presence of $\mathrm{SO}_{2}$ throughout the solids phase and over the whole reactor length is assumed. At $190^{\circ} \mathrm{C}$ we varied the excess of $\mathrm{SO}_{2}$ and did not find a significant effect on the $\mathrm{H}_{2} \mathrm{~S}$ conversion. At temperatures of about $200^{\circ} \mathrm{C}$ the conversion of $\mathrm{H}_{2} \mathrm{~S}$ and $\mathrm{SO}_{2}$ may become affected by the thermodynamic equilibrium of the Claus reaction (Gamson and Elkins, 1953), and this was actually observed in separate experiments with the present zeolite catalyst (Verver, 1984). Nevertheless, calculation showed negligible effect of thermodynamic limitations on the $\mathbf{H}_{2} \mathrm{~S}$ conversion to exist in the present experiments, due to the excess of $\mathrm{SO}_{2}$ used.

For the mass transfer experiments the value of $k_{\text {ov }}$ was obtained from the conversion of $\mathrm{H}_{2} \mathrm{~S}$, by using eq. (6). Resulting data are given in Table 4 . In the case of an instantancous reaction at the catalyst phase, the overall rate constant $k_{\text {ov }}$ would correspond to the gasphase mass transfer rate constant $k_{\mathrm{g}} a$. The gas-solid interfacial area $a$ can be considered a constant at given $u_{\mathrm{g}}$ and $S$, assuming that the solids hold-up is independent of temperature. The mass-transfer coefficient $k_{\mathrm{g}}$ is influenced only slightly by temperature. At most, $k_{\mathrm{g}}$ is proportional to the gas diffusion coefficient, which can be written as a power function of $T$, the exponent being between 1.6 and 1.8 (see, e.g., Satterfield, 1970). Therefore, in the case of pure mass transfer limitation, the apparent activation energy of the mass transfer rate constant will be low: typically less than about $6 \mathrm{~kJ} \mathrm{~mol}^{-1}$. The $k_{\mathrm{ov}}$ data obtained at temperatures below $150^{\circ} \mathrm{C}$ show an apparent activation energy of at least $15 \mathrm{~kJ} \mathrm{~mol}^{-1}$, but above $150^{\circ} \mathrm{C} \mathrm{a}$ value of about $6 \mathrm{~kJ} \mathrm{~mol}^{-1}$ is observed. This suggests that for the $\mathrm{H}_{2} \mathrm{~S}-\mathrm{SO}_{2}$ experiments at 150 and $190^{\circ} \mathrm{C}$, the $\mathrm{H}_{2} \mathrm{~S}$ conversion is determined by mass transfer rather than kinetic phenomena. Using the $k_{\text {ov }}$ data of Table 4, we derived for the mass transfer rate constant the following empirical correlation, which is valid for the experiments at $u_{\mathrm{g}}=0.15 \mathrm{~m} \mathrm{~s}^{-1}$ :

$$
\begin{aligned}
k_{\mathrm{g}} a= & \left\{92.0 \times 10^{-6}\left[\mathrm{~S} /\left(\mathrm{kg} \mathrm{m}^{-2} \mathrm{~s}^{-1}\right)\right]^{0.4}\right. \\
& \left.\times(T / K)^{1.75}\right\} \mathrm{s}^{-1}
\end{aligned}
$$

The value of $k_{\mathrm{ov}}$ should be proportional to the interfacial area, which again is a function of the solids hold-up and the solids mass flux. It appears that $k_{\text {ov }}$ is proportional to $S^{0.4}$, while the solids hold-up is proportional to $S^{\mathbf{0 . 8}}$ (Verver, 1984). If $k_{\mathrm{g}}$ is assumed to be independent of $S$, this would support a cylindrical geometry of the trickles. Furthermore, our data can be compared with mass transfer data given by Roes and Van Swaaij (1979c) for gas-solid trickle flow in a packed column. At solids mass fluxes of 2-6 $\mathrm{kg} \mathrm{m}^{-2} \mathrm{~s}^{-1}$ and using a Pall rings packing, they found at $u_{\mathrm{g}}=0.15 \mathrm{~m} \mathrm{~s}^{-1}$ a height of a true transfer unit for Freon adsorption of about $0.05 \mathrm{~m}$, which means a $k_{\mathrm{g}} a$ value of about $3.0 \mathrm{~s}^{-1}$. This is only slightly above the $k_{\mathrm{g}}$ a value found in our experiments, whereas in their experiments the solids hold-up was higher by a factor of 20-100. Again, this indicates that the gasphase mass transfer rate constant depends on the trickle-phase surface area rather than on the particle surface area.

\section{REACTOR MODEL CALCULATIONS}

The reactor model presented describes the overall rate constant $k_{\text {ov }}$ as a function of the gas-phase mass transfer rate constant, $k_{\mathrm{g}} a$, and the effective reaction rate constant, $\beta k_{\mathrm{r}} \eta_{\mathrm{tr}}$, which takes into account the trickle-phase diffusion resistance. Data on the catalyst hold-up, $\beta$, are available from the tracer experiments, where we assumed that $\beta$ is only a function of gas velocity and catalyst mass flux, and not of temperature. The apparent reaction rate constant, $k_{\mathrm{r}}$, follows from the chemical reaction rate data obtained separately, which were combined into a first-order reaction rate constant, $k_{\text {chem }}$, in eq. (12). At low temperature, $k_{\mathrm{r}}$ is equal to $k_{\text {chem }}$, but at elevated temperatures, above $200^{\circ} \mathrm{C}, k_{\mathrm{r}}$ is affected by pore diffusion resistance, resulting in slightly lower values for $k_{\mathrm{r}}$ than for $k_{\text {chem }}$ (see

Table 4. Experimental results of mass transfer experiments $\left(u_{\mathrm{g}}=0.15 \mathrm{~m} \mathrm{~s}^{-1}\right)$

\begin{tabular}{cccccc}
\hline $\begin{array}{c}T \\
\left({ }^{\circ} \mathrm{C}\right)\end{array}$ & $\begin{array}{c}S \\
\left(\mathrm{~kg} \mathrm{~m}^{-2} \mathrm{~s}^{-1}\right)\end{array}$ & $\zeta_{\mathrm{H}_{2} \mathrm{~S}}$ & $\zeta_{\mathrm{SO}_{2}}$ & $\begin{array}{c}X \mathrm{X} \\
\left(\mathrm{kg} \mathrm{S} \mathrm{kg}^{-1}\right)\end{array}$ & $\begin{array}{c}k_{\text {ov }} \\
\left(\mathrm{s}^{-1}\right)\end{array}$ \\
\hline 110 & 0.022 & 0.840 & 0.83 & 0.048 & 0.46 \\
110 & 0.031 & 0.884 & 0.95 & 0.037 & 0.54 \\
150 & 0.022 & 0.957 & 0.80 & 0.052 & 0.79 \\
150 & 0.031 & 0.972 & 0.91 & 0.038 & 0.90 \\
190 & 0.016 & 0.962 & 0.62 & 0.059 & 0.82 \\
190 & 0.022 & 0.973 & 0.69 & 0.045 & 0.90 \\
190 & 0.031 & 0.986 & 0.75 & 0.033 & 1.06 \\
\hline
\end{tabular}

tSulphur load of catalyst leaving the reactor, as calculated from the sulphur mass balance of the reactor. 
Table 2). The trickle-phase effectiveness factor, $\eta_{\mathrm{tr}}$, depends on solids hold-up, reaction rate constant and trickle-phase geometry. In the trickle-phase model, a description of the geometric properties has been given, resulting in the equations for the trickle-phase Thiele modulus and effectiveness factor [eqs (10) and (7), respectively]. Using the $k_{\mathrm{r}}$ and $\beta$ data above, the trickle-phase effectiveness factor was calculated as a function of $S$ for a trickle-phase porosity of 0.90 and 0.99 , respectively (Fig. 8). Trickle-phase diffusion appears to offer significant resistance to the overall mass transfer rate at temperatures of $200^{\circ} \mathrm{C}$ and above, particularly at the higher solids mass fluxes. The effect of the $\varepsilon_{\mathrm{qr}_{\mathrm{r}}}$ value on $\eta_{\mathrm{tr}}$ is rather small, only a few per cent, which was to be expected because in eq. $(10), \varepsilon_{\mathrm{tr}}$ is involved indirectly only, namely via $D_{\mathrm{tr}, \mathrm{efr}}$. In the case of strong diffusional limitations (i.e. at $\phi_{\mathrm{tr}}>1$, or $\eta_{\mathrm{tr}}$ less than about 0.7 ), the maximum effect on $\eta_{\mathrm{tc}}$ occurs: for example, $20 \%$ if $\varepsilon_{\mathrm{qr}}$ is as low as 0.8 , which would correspond to a trickle-phase hold-up of 100-200 times the average hold-up. At $T>300^{\circ} \mathrm{C}, k_{\mathrm{T}}$ increases relatively slowly with temperature due to pore diffusion resistance and, accordingly, $\eta_{\mathrm{tr}}$ decreases but slowly at increasing temperature, as can be seen in Fig. 8.

Using the data on $k_{\mathrm{r}}, \beta$ and $\eta_{\mathrm{tr}}$ described above, and the gas-phase mass transfer rate constant data given in eq. (18), the overall rate constant $k_{\text {ov }}$ was calculated from eq. (4). Results are presented in Fig. 9 (line a). Expcrimental data on $k_{\mathrm{ov}}$ are shown as well. At $200^{\circ} \mathrm{C}$, the data on $k_{\text {ov }}$ (both the calculated and the experimental data) are about one order of magnitude less than $k_{\mathrm{g}} a$ (line $\mathrm{d}$ ), which means negligible mass transfer resistance at the gas-solids interface. At $300^{\circ} \mathrm{C}$, however, $k_{\mathrm{g}} a$ greatly affects the overall rate. Besides this, the trickle-phase model predicts a substantial decrease of $\eta_{\mathrm{tr}}$ above $200^{\circ} \mathrm{C}$, which results in $k_{\mathrm{ov}}$ values significantly less than as would have been

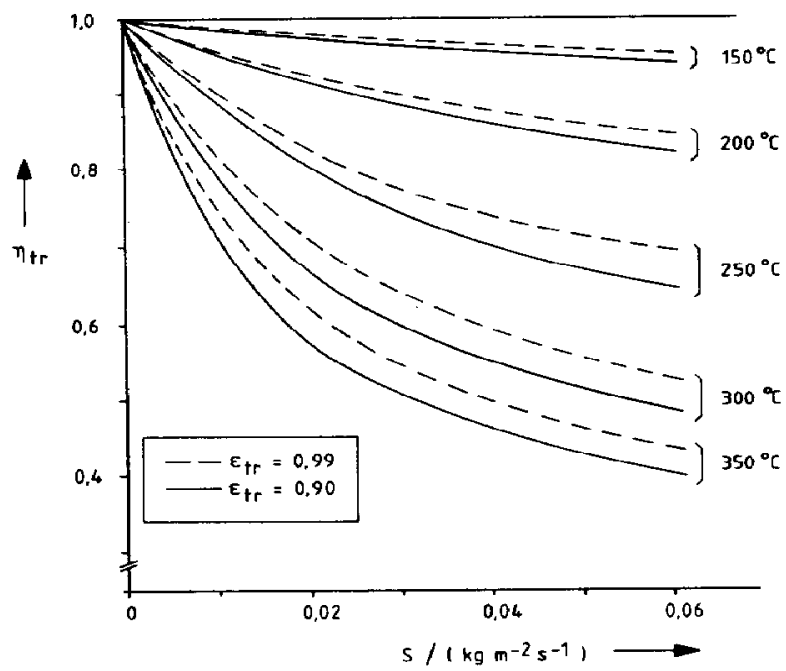

Fig. 8. The effectiveness factor of the trickle phase vs solids mass flux, as calculated from the trickle-phase model.

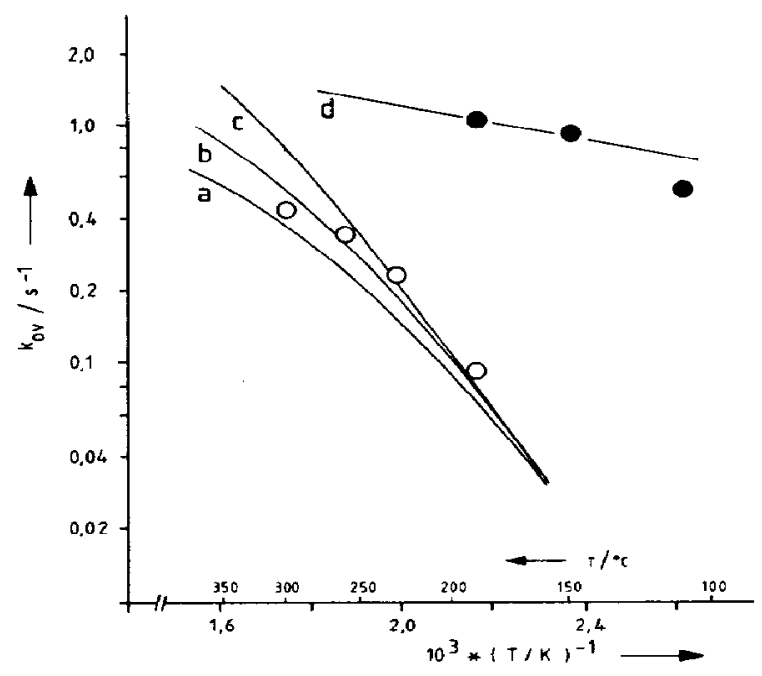

Fig. 9. The overall rate constant vs reciprocal temperature $\left(S=0.03 \mathrm{~kg} \mathrm{~m}^{-2} \mathrm{~s}^{-1}\right)$. Experimental data: 0 mass transfer experiments $\left(\mathrm{H}_{2} \mathrm{~S}-\mathrm{SO}_{2}\right.$ reaction); $\mathrm{O}_{2}$ S-oxidation experiments $\left(\mathrm{H}_{2} \mathrm{~S}-\mathrm{O}_{2}\right.$ reaction). Theoretical curves: (a) $k_{\mathrm{ov}}$ from trickle-phase model [eq. (4)]; (b) no trickle-phase mass transfer limitations $\left[k_{\mathrm{ov}}=\left(1 / k_{\mathrm{g}} a\right)+\left(1 / k_{\mathrm{r}} \beta\right)\right]$; (c) no gasphase or trickle-phase mass transfer limitations $\left(k_{\mathrm{ov}}=k_{\mathrm{r}} \beta\right)$;

(d) gas-phase mass transfer rate constant [eq. (18)].

obtained from the reaction rate data only $\left(k_{\mathrm{r}} \beta\right.$, line $\left.\mathrm{c}\right)$. This corresponds remarkably well with the drop in overall reactor efficiency shown by the experiments. A model neglecting trickle-phase diffusion resistances (line b) does show a decreasing overall reactor efficiency, but not to such an extent as is shown by the experimental data. So, the reactor model preferably should include the trickle-phase mass transfer resistance (line a).

In the present reactor model, only trickle-phase diffusion resistance and intraparticle (pore) diffusion resistance is considered, while mass transfer resistance to the particle surface has been neglected. For the present application, using rather small particles, the solids surface area in the reactor is high, about $50-100 \mathrm{~m}^{2}\left(\mathrm{~m}^{3} \text { reactor volume }\right)^{-1}$. Assuming that the mass transfer coefficient to the particle surface is equal to that of mass transfer to a spherical particle at low Reynolds number, i.e. the Sherwood number amounts to 2.0, we found mass transfer rate constants of about two orders of magnitude above the $k_{\text {ov }}$ values observed in the mass transfer experiments. Although the assumption for the Sherwood number might be somewhat optimistic because in fluidized-bed systems at low Reynolds numbers lower $S h_{\mathrm{p}}$ numbers are found (see, e.g., Westerterp et al., 1984), it should not be considered as an unrealistic one, because the porosity in the trickle phase is not likely to be as low as in the dense phase of a packed or a fluidized bed. A local solids hold-up of $10-100$ times the average hold-up still corresponds to porosities of $0.90-0.99$ only.

The experimental data on $k_{\mathrm{ov}}$ obtained at $u_{\mathrm{g}}$ $=0.15 \mathrm{~m} \mathrm{~s}^{-1}$ and at solids mass fluxes up to 


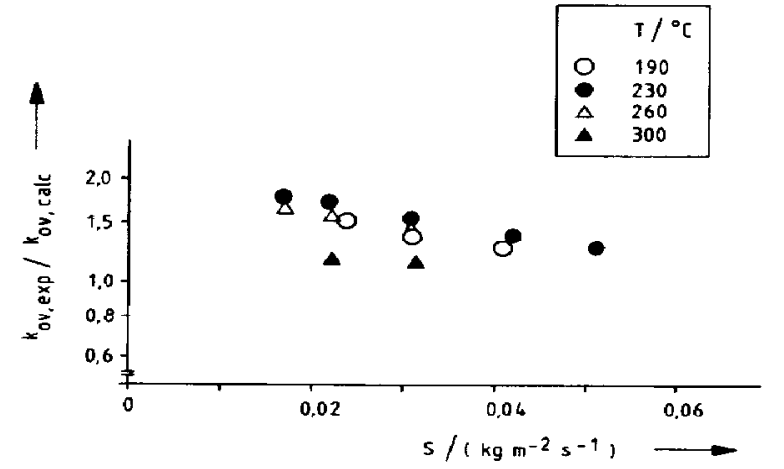

Fig. 10. Comparison of experimental and calculated $k_{\text {ov }}$ data vs solids mass flux $\left(u_{\mathrm{g}}=0.15 \mathrm{~m} \mathrm{~s}^{-1}\right)$.

$0.05 \mathrm{~kg} \mathrm{~m}^{-2} \mathrm{~s}^{-1}$ (Fig. 6) are compared to those predicted by the trickle-phase reactor model, see Fig. 10. Experimental data were used only if the sulphur load of the catalyst had been less than $0.04 \mathrm{~kg} \mathrm{~S} \mathrm{~kg}^{-1}$, in order to permit axial differences in $k_{\mathrm{r}}$ to be neglected. Generally, the experimental data are about $20-60 \%$ above the theoretical value. This deviation is observed at each temperature, including those without mass transfer limitations. Therefore, we may ascribe the differences to a higher catalyst hold-up in the $\mathrm{H}_{2} \mathrm{~S}$ oxidation reactor as compared to the hold-up measured at room temperature. This may be due to the higher gas viscosity in the reactor, or possibly due to higher particle-baffle frictional forces. Apart from this, the agreement between experimental and calculated $k_{\text {ov }}$ data appears to be fairly good at all solids mass fiuxes applied.

\section{CONCLUSIONS}

In the present investigations it has been demonstrated that oxidation of $\mathrm{H}_{2} \mathrm{~S}$ with $\mathrm{O}_{2}$ producing sulphur from a $\mathrm{H}_{2} \mathrm{~S}$-contaminated gas at $200-300^{\circ} \mathrm{C}$, can be carried out in a gas-solid trickle-flow reactor at low solids-to-gas mass flux ratios, using a NaX zeolite both as a catalyst and as an adsorbent of the sulphur product.

The conversion over the reactor is described most preferably by a model which considers mass transfer in the gas-solid suspension phase, or trickle phase. Trickle-phase diffusion can be an important factor in the performance of such a reactor, particularly if small particles are being used, as these might show severe particle agglomeration effects.

The gas-phase mass transfer rate constant, as determined by the reaction of $\mathrm{H}_{2} \mathrm{~S}$ with $\mathrm{SO}_{2}$, and catalyst hold-up in the reactor are found to depend on the solids mass flux, but to a different degree. Gas-phase mass transfer is most likely determined by a gasphase/trickle-phase interfacial area, rather than by the particle surface area.

The performance of the $\mathrm{H}_{2} \mathrm{~S}$-oxidation reactor, which is expressed as the overall rate constant for a plug flow reactor, is hardly affected by mass transfer resistance at low temperatures, i.e. up to $200^{\circ} \mathrm{C}$. At

higher temperatures, mass transfer limitations are becoming important, as is clear from by the decrease in the apparent activation energy.

The trickle-phase reactor model predicts the absence of mass-transfer limitations at temperatures below $200^{\circ} \mathrm{C}$. At higher temperatures, both the gas-phase mass transfer rate and diffusion rate into the trickle phase, and, to a lesser extent, the intraparticle diffusion rate, offer a significant resistance to the overall rate. At all temperatures applied, the agreement with the experimentally observed data is reasonably good.

Although the trickle-phase model is based on simplifying assumptions concerning the trickle-phase porosity, the hydrodynamics of the trickle phase and the trickle geometry, it describes the experiments in the $\mathrm{H}_{2}$ S-oxidation reactor fairly well. Apart from the advantage that it considers the effect of particle agglomeration, it also provides an improved fit to the experimental data.

Because of the unfavourable effect of trickles, it seems worthwhile to investigate the application of larger particles. In this case, probably less pronounced trickle formation may lead to equally attractive mass transfer properties, whereas higher gas velocities can be applied, which is favourable for technical application of this $\mathrm{H}_{2} \mathrm{~S}$-removal process.

Acknowledgements-Thanks are due to P. L. Eijsberg and J. Pek for their contribution to the experimental programme and to Akzo Chemie B. V., Research Centre Amsterdam, for specially preparing the zeolite catalyst.

\section{NOTATION}

$\boldsymbol{A}$

$a$

c

$c_{\mathbf{i}}$

C

$d_{\text {pore }}$

$d_{\mathrm{tr}}$

D

$D_{\text {eff }}$

$D_{\mathrm{kn}}$

E

$k_{\text {chem }}$

$k_{\mathrm{g}}$

$k_{\mathrm{g}} a$

$k_{\text {ov }}$

$k_{\mathrm{T}}$

L

$M$

$\mathrm{Pe}$

R

$S$

$S h_{\mathrm{p}}$ $t$

$T$

$u_{\mathrm{g}}$ external surface area, $\mathbf{m}^{2}$ interfacial area, $\mathrm{m}^{2}\left(\mathrm{~m}^{3} \text { reactor }\right)^{-1}$ gas-phase concentration, mol $\mathrm{m}^{-3}$ gas-phase concentration at interface, mol $\mathrm{m}^{-3}$

tracer concentration in RTD experiments (arbitrary units)

average pore diameter, $m$

average diameter of trickle, eq. (9), m

gas diffusion coefficient, $\mathrm{m}^{2} \mathrm{~s}^{-1}$

effective diffusion coefficient, $\mathrm{m}^{2} \mathrm{~s}^{-1}$

Knudsen diffusion coefficient, $\mathrm{m}^{2} \mathrm{~s}^{-1}$ activation energy, $\mathrm{J} \mathrm{mol}^{-1}$

chemical reaction rate constant; $s^{-1}$ gas-phase mass transfer coefficient, $\mathrm{m} \mathrm{s}^{-1}$

gas-phase mass transfer rate constant, $s^{-1}$ overall rate constant, $s^{-1}$

apparent reaction rate constant, $k_{\text {chem }} \eta_{p}, s^{-1}$

length of reactor, $\mathrm{m}$

molecular mass, $\mathrm{kg} \mathrm{mol}^{-1}$

Péclet number, $u_{\mathrm{g}} L / D$

gas constant, $J \mathrm{~mol}^{-1} \mathrm{~K}^{-1}$

solids mass flux, $\mathrm{kg} \mathrm{m}^{-2} \mathrm{~s}^{-1}$

particle Sherwood number, $k_{\mathrm{g}} d_{\mathrm{p}} / D$

time, s

temperature, $\mathbf{K}$

superficial gas velocity, $\mathrm{m} \mathrm{s}^{-1}$ 
$u_{\mathrm{p}} \quad$ mean particle velocity, $\mathrm{m} \mathrm{s}^{-1}$

$V_{\mathrm{r}} \quad$ reactor volumc, $\mathrm{m}^{3}$

$V \quad$ volume, $\mathrm{m}^{3}$

$x \quad$ distance from gas inlet, $\mathrm{m}$

$X_{\mathrm{S}} \quad$ sulphur load of catalyst, $\mathrm{kgS}\left(\mathrm{kg}\right.$ catalyst) ${ }^{-1}$

\section{Greek letters}

$\beta \quad$ solids hold-up, $\mathrm{m}^{3}$ solids $\mathrm{m}^{-3}$

e porosity

$\zeta \quad$ degree of conversion, $1-c_{\text {out }} / c_{\text {in }}$

$\theta$ tortuosity of the trickle

$\eta \quad$ effectiveness factor

$\rho_{\mathrm{p}} \quad$ particle density, $\mathrm{kg} \mathrm{m}^{-3}$

$\tau$ tortuosity factor for catalyst pores

$\bar{\tau} \quad$ mean residence time of the solids, $s$

$\phi \quad$ Thiele modulus, eqs (8) and (14)

\section{Subscripts}

in at gas inlet

out at gas outlet

p referring to catalyst particle

tr referring to trickle phase

\section{REFERENCES}

Barrer, R. M. and Whitcman, J. L., 1967, Intracrystalline sorption of sulphur and phosphorus by some porous crystals. $J$. Chem. Soc. A, 13.

Gamson, B. W. and Elkins, R. H., 1953, Sulfur from hydrogen sulfide. Chem. Engng Prog. 49, 203.

Johnson, G. C. and Kerr, G. T., 1961, Process for recovering sulfur from hydrogen sulfide-containing gases. U.S.A. Patent 2971824.
Kohl, A. L. and Riesenfeld, R. C., 1979, Gas Purification. Gulf Publishing Co., Houston, TX.

Noordergraaf, I. W., Roes, A. W. M. and Van Swaaij, W. P. M., 1980, Axial mixing and mass transfer in a zig-zag contactor, Proc. 3rd Int. Conference on Fluidization, New Hampshire.

Roes, A. W. M. and Van Swaaij, W. P. M., 1979a, Hydrodynamic behaviour of a gas-solid counter-current packed column at trickle flow, Chem. Engng J. 17, 81 .

Roes, A. W. M. and Van Swaaij, W. P. M., 1979b, Axial dispersion of gas and solid phases in a gas-solid packed column at trickle flow, Chem. Engng J. 18, 13.

Roes, A. W. M. and Van Swaaij, W. P. M., 1979c, Mass transfer in a gas-solid packed column at trickle flow, Chem. Engng J. 18, 29.

Satterfield, C. N., 1970, Mass Transfer in Heterogeneous Catalysis. MIT Press, Cambridge, MA.

Verver, A. B., 1984, The catalytic oxidation of hydrogen sulphide to sulphur in a gas-solid trickle-flow reactor. Ph.D. thesis, Twente University of Technology, Enschede, The Netherlands.

Verver, A. B. and Van Swaaij, W. P. M., 1984, Modelling of a gas-solid trickle-flow reactor for the catalytic oxidation of hydrogen sulphide to elemental sulphur, Proc. $8 \mathrm{th}$ Int. Symp. Chemical Reaction Engineering, Edinburgh, Inst. Chem. Engrs Symp. Ser. No. 87, 177.

Verver, A. B. and Van Swaaij, W. P. M., 1985, The rate of oxidation of hydrogen sulphide by oxygen to elemental sulphur over $\mathrm{NaX}$ and $\mathrm{NaY}$ zeolites and the adsorption of sulphur. Appl. Catal. 14, 185.

Verver, A. B. and Van Swaaij, W. P. M., 1986a, The hydrodynamic behaviour of gas-solid trickle flow over a regularly stacked packing. Powder Technol. 45, 119.

Verver, A. B. and Van Swaaij, W. P. M., 1986b, The heat transfer performance of gas-solid trickle flow over regularly stacked packings. Powder Technol. 45, 133.

Weisz, P. B. and Hicks, J. S., 1962, The behaviour of porous catalyst particles in view of internal mass and heat diffusion effects. Chem. Engng Sci. 17, 265.

Westerterp, K. R., Van Swaaij, W. P. M. and Beenackers, A. A. C. M., 1984, Chemical Reactor Design and Operation. Wiley, New York. 